$\begin{array}{cl}\begin{array}{cl}\text { Revue } \\ \text { del'histoire }\end{array} & \text { Revue de l'histoire des religions } \\ \text { des religions } & 2 \mid 2006 \\ & \text { Varia }\end{array}$

\title{
Le droit chemin
}

L'ange gardien, instrument de disciplinarisation après la Contre-Réforme The Right Path. Guardian Angel as an Instrument for Disciplinarisation after the Counter-Reformation

\section{Anne Manevy}

\section{(Q) OpenEdition Journals}

Édition électronique

URL : http://journals.openedition.org/rhr/5152

DOI : $10.4000 /$ rhr.5152

ISSN : 2105-2573

\section{Éditeur}

Armand Colin

\section{Édition imprimée}

Date de publication : 1 juin 2006

Pagination : 195-227

ISBN : 2200-92104-7

ISSN : 0035-1423

Référence électronique

Anne Manevy, "Le droit chemin », Revue de l'histoire des religions [En ligne], 2 | 2006, mis en ligne le 20 janvier 2010, consulté le 23 avril 2019. URL : http://journals.openedition.org/rhr/5152 ; DOI : 10.4000/ rhr.5152 
ANNE MANEVY

Centre d'anthropologie, UMR 8555

(EHESS/Université de Toulouse-le-Mirail)

\section{Le droit chemin L'ange gardien, instrument de disciplinarisation après la Contre-Réforme}

Dans le catholicisme, le lien établi entre un individu et son ange tutélaire rappelle la relation de patronage, propre au culte des saints. Bien adapté au discours clérical de la Contre-Réforme, en particulier au discours jésuitique sur les «Fins Dernières » et à l'idéal de sanctification personnelle, le bon ange s'impose surtout comme une conscience morale extériorisée qui trouve place dans un système d'édification. Si, pour l'Église, l'ange gardien présente l'avantage d'orienter la piété des fidèles vers les cultes centraux du catholicisme (Christ et Vierge), il n'en demeure pas moins une figure susceptible de s'adapter à des niveaux de religiosité différents, selon un mouvement de féminisation et d'infantilisation.

\section{The Right Path. Guardian Angel as an Instrument for Disciplinarisation after the Counter-Reformation.}

In Catholicism, the link between an individual and his protective angel recalls the relationship of patronage within the cult of the saints. Welladapted to the clerical discourse of the Counter-Reformation, particularly to the Jesuit discourse on the "Final Judgment" and the ideal of personal sanctification, the good angel imposes itself primarily as an externalized moral conscience which has its place in a system of edification. If, for the Church, the guardian angel has the advantage of orienting the piety of the faithful towards the central cults of Catholicism (Christ and the Virgin Mary), it nevertheless remains a figure likely to be adapted to different levels of religiosity, according to movement towards feminization and infantilization. 
Au cours des siècles, l'Église a décrit un ange tutélaire, bienveillant et anonyme, attitré à la garde de chaque individu. Comparativement à d'autres figures du panthéon catholique, cet ange gardien a été peu étudié. On sait cependant qu'avant de s'établir dans le champ de la piété individuelle, il fut d'abord l'objet d'un culte civique, assigné à la protection d'une collectivité locale en particulier ${ }^{1}$. La fête des saints anges gardiens, fixée au 2 octobre, est étendue à l'Église universelle au $\mathrm{XVII}^{\mathrm{e}}$ siècle et, usant de tous ses outils de validation traditionnels - normes liturgiques, ouvrages de piété, sermons, iconographie, approbations, indulgences, confréries...-, l'autorité ecclésiale s'est appliquée à définir cette figure du «bon ange député à la garde de chaque fidèle », relevant de ce que Jean Delumeau appelle le «vaste mouvement de sécurisation », et signe de la piété individuelle. Dans la piété tridentine, l'ange gardien personnel est surtout un auxiliaire de la Bonne Mort dont la préparation embrasse tout le temps de l' « épreuve ». Du même coup, il est aussi celui qui protège contre la mort subite et, par sa veille accrue, prévient les accidents. Progressivement, l'ange gardien va participer d'un système d'édification, intervenant auprès des enfants à la manière d'une conscience morale, encourageant la modestie, la bonne conduite et tout ce qui maintient le chrétien dans le « droit chemin ». Dès lors, il est vivement encouragé de se recommander sans cesse à ce compagnon invisible, à ce « fidèle ami », adversaire des tentations et des mauvais penchants. Mais, dans ce vaste processus de disciplinarisation, la fonction tutélaire du «bon ange» recoupe les prérogatives d'une autre figure, celle du saint patron.

1. Cette relation de patronage entre un ange gardien et une collectivité - une municipalité le plus souvent - est attestée dans certaines localités de la péninsule ibérique à la fin du Moyen Âge. $C f$. Gabriel Llompart, «El Angel Custodio en la Corona de Aragón en la Baja Edad Media (fiesta, teatro, iconografia) » in Fiestas y Liturgia, Madrid, 1988, p. 249-269 ; Jean Delumeau, «Un géant magnanime » in Rassurer et protéger, Le sentiment de sécurité dans l'Occident d'autrefois, Fayard, Paris, 1989, p. 293-339; Jacqueline Hadziiossif, "L'Ange Custode de Valence » in La religion civique à l'époque médiévale et moderne. Chrétienté et Islam, A. Vauchez (éd.), École française de Rome, 1995, p. 135-152. 


\section{L'ANGE CONDUCTEUR DE L'ÂME ET LA BONNE MORT}

À l'époque médiévale, l'ange gardien personnel apparaît dans un certain nombre de poésies composées par des religieux lettrés ${ }^{2}$. En langue vulgaire, les prières à l'ange tutélaire, au « propre ange », semblent dater du XIV ${ }^{\mathrm{e}}$ siècle. Généralement établies à la première personne, ces prières insistent sur le salut de l'âme - l'instant du jugement est capital - et évoquent les tentations que le bon ange, l'ange «commis », doit permettre d'écarter ${ }^{3}$. Après la Réforme, c'est sur cette protection lors des « Fins Dernières » que l'Église entend fonder sa pastorale de l'ange gardien personnel, par le biais notamment de toute une «littérature de vulgarisation théologique et de spiritualité ${ }^{4} »$. À cet égard, les membres de la Compagnie de Jésus s'illustrent avec un très grand nombre de publications : Albertini, Libellus de Angelo Custode (1613) ; Drexelius, Horologium tutelarium angelis (1622); Suarez, De Angelis (1630) ${ }^{5}$; Paul de Barry, La Dévotion aux anges (1641), etc. D'une manière générale, la dévotion à l'ange gardien va singulièrement bénéficier de l'organisation apostolique mise en place par la Compagnie qui, depuis ses collèges, rayonne au moyen des congrégations mariales ${ }^{6}$, des retraites et des missions.

Le père jésuite Jacques Coret, né à Valenciennes en 1631 et mort à Liège en 1721, est considéré comme l'un des grands propagateurs de la dévotion à l'ange gardien. Il est, entre autres, l'auteur d'une somme d'ouvrages sur la question qui connaîtront de nombreuses

2. Henry Spitzmuller a retranscrit un certain nombre de ces textes dans Poésie latine chrétienne du Moyen Âge. III -XVe siècle, Desclée de Brouwer, 1971.

3. Pierre Rézeau, Les Prières aux saints en français à la fin du Moyen Âge, vol. 2, Droz, Genève, 1983, p. 512.

4. Bernard Dompnier, «Des Anges et des signes. Littérature de dévotion à l'ange gardien et image des anges au XVII ${ }^{\mathrm{e}}$ siècle » in Les signes de Dieu aux $X V I^{e}$ et XVII siècles, Faculté de lettres et sciences humaines de l'université Blaise Pascal, Clermont-Ferrand, fasc. 41, 1993, p. 211.

5. Imposant ouvrage posthume du théologien Francisco Suarez (1548-1617).

6. On appelle congrégations mariales des associations religieuses placées sous le patronage de la Vierge, initiées par la Compagnie de Jésus. Le recrutement des congréganistes est sélectif (par classe d'âge, condition, etc.). 
rééditions, et ce pendant des décennies. L'Ange Gardien protecteur spécialement des mourans (1662), La Bonne Mort sous la protection des Sts Anges Gardiens, présentée aux personnes qui pensent sérieusement à bien mourir (1663), l'Ange conducteur dans la dévotion chrétienne ou Pratiques pieuses en faveur des âmes dévotes; avec une instruction sur les grandes indulgences dont jouissent les personnes associées dans la Confrérie de l'Ange gardien (1683), La conduite de l'Ange dans le choix de l'un ou l'autre des cinq états suivans, ecclésiastique, religieux, de célibat, de mariage, et de viduité et dans les moyens qu'il y avance pour s'y sauver (1697) ${ }^{7}$, tels sont quelques-uns de ces titres, fort éloquents et souvent remaniés au cours des éditions successives, témoins d'une volonté de prédication quant à la préparation à la mort, à la «Bonne Mort ». Son très populaire Ange conducteur, publié pour la première fois à Liège en 1683, connaît une importante diffusion avec plus de cinq cents éditions ou réimpressions, les éditions se multipliant surtout après $1740^{8}$. L'ouvrage, diffusé tant par les libraires que les réseaux de colportage, s'apparente à un livre d'heures et propose des exercices de piété quotidiens. S'il s'inscrit lui aussi dans la tradition des Préparations à la mort, c'est, selon Michel Vernus qui l'étudia, sans recourir à la " pédagogie de la peur ${ }^{9}$ ». Ces préparations constituent une des thématiques privilégiées de la pastorale catholique d'alors et de nombreux manuels rédigés par des Jésuites leur accordent une place prépondérante ${ }^{10}$. Cette « ascèse d'une mort quotidienne », comme la définit Michel Vovelle ${ }^{11}$, prend, à la fin du XVII ${ }^{e}$ et au début du $\mathrm{XVIII}^{\mathrm{e}}$ siècle, des allures de longue préparation, la bonne mort nécessitant constance et rigueur quotidienne, différant en cela des

7. Carlos Sommervogel, Bibliothèque de la Compagnie de Jésus, Bibliographie, t. II, O. Schepens, Bruxelles ; A. Picard, Paris, 1891.

8. Michel Vernus, «Un Best-seller de la littérature religieuse : L'Ange Conducteur (du XVII ${ }^{\mathrm{e}}$ au XIX ${ }^{\mathrm{e}}$ siècle) $)$ in Transmettre la foi $: \mathrm{XVI}^{e}-\mathrm{XX}$ siècles, vol. 1 : Pastorale et prédication en France, CTHS, Paris, 1984, p. 231-243.

9. Ibid., p. 238.

10. Notamment les pères Jean Crasset (La belle mort, 1653 - La douce et sainte mort, 1681- Préparation à la mort, 1689) et Paul de Barry (Pensez-y bien ou réflexions sur les quatre fins dernières). p. 292.

11. La Mort et l'Occident de 1300 à nos jours, Gallimard, Paris, 1983, 
Artes moriendi qui se sont répandus en Occident du milieu du $\mathrm{XV}^{\mathrm{e}}$ au milieu du $\mathrm{XVI}^{\mathrm{e}}$ siècle, centrés sur les tentations pendant l'agonie, vaincues par autant d'inspirations angéliques, et dont la spectaculaire iconographie présente un moribond alité ${ }^{12}$. Chez Jacques Coret, la dévotion à l'ange gardien n'est pas dissociable de cette préparation à la mort et le modèle de confrérie en l'honneur de l'ange gardien qu'il entend populariser est avant tout une confrérie de la Bonne Mort. La titulature de l'ange gardien pour ces associations dites de la Bonne Mort n'est pas rare en effet, surtout dans le Nord et en Flandre. L'Association jésuite romaine de Jésus mourant sur la Croix et de sa mère la Vierge Marie souffrant sous la Croix ou de la Bonne Mort érigée dans l'église du Gesù en 1648, et qui deviendra archiconfrérie en 1729, insiste sur la préparation individuelle à la mort, les exercices pouvant être effectués en privé ne nécessitant pas une vie confraternelle intense ni une réglementation trop rigoureuse de la vie collective ${ }^{13}$. Le manuel de la confrérie de la Bonne Mort érigée dans l'église Saint-Pierre à Clermont, indulgenciée par une bulle du pape Clément XI en 1701, stipule que les personnes associées « adresseront chaque jour quelques courtes mais ferventes prières à la sainte Vierge, à saint Joseph ${ }^{14}$ et au saint Ange

12. Henri Zerner, «L'Art au morier », Revue de l'Art, n 11, 1971, p. 7-30. Roger Chartier, « Les arts de mourir, 1450-1600», Annales E.S.C., n 1, 1976, p. 51-75. Daniel Roche, «La mémoire de la mort. Recherche sur la place des arts de mourir dans la Librairie et la lecture en France aux XVII e et XVIII ${ }^{\mathrm{e}}$ siècles », ibid., p. 76-119.

13. Sur cette question, ainsi que sur les rapports entre l'Association de la Bonne Mort et une autre confrérie importante, celle des Agonisants, j'ai consulté Françoise Hernandez, «Les confréries de l'Agonie de Jésus et des Agonisants à la lumière de leurs livrets et manuels », Siècles, n ${ }^{\circ}$ 12, 2000, p. 29-56.

14. Du reste, le XVII e siècle voit également l'essor spectaculaire d'une autre dévotion, le culte rendu à saint Joseph, « patron de la bonne mort », fort de sa mort idéale, entouré de la Vierge, du Christ, de saint Jean-Baptiste, des anges, de saint Michel. Rome confirme le culte officiel de chacune de ces dévotions au même moment et c'est un même pape, Clément X, qui, en 1670, rend obligatoires la fête des saints anges gardiens et celle de saint Joseph et les étend à l'Église universelle. Jean Delumeau, qui a relevé cette simultanéité, fait aussi remarquer que les auteurs ayant écrit sur l'ange gardien sont ceux-là mêmes qui ont beaucoup écrit sur saint Joseph, autrement dit, dans la plupart des cas, des Jésuites, op. cit., p. 340-341. 
Gardien », le mardi étant consacré à la récitation des litanies des saints anges ${ }^{15}$.

C'est encore l'ange gardien qui est aux côtés du mourant dans ce genre iconographique dit Miroir de l'âme. L'ange est celui qui veille sur l'âme, depuis la conception jusqu' au fameux « Jugement». Traditionnellement, le diable montre au moribond ses mauvaises actions, dans le but de l'inciter au désespoir, tandis que l'ange l'exhorte à la confiance dans la miséricorde divine. L'ange et le diable tiennent respectivement un livre des bonnes actions et un livre des mauvaises, biographies antagonistes destinées à sauver ou damner l'âme au moment de la mort ${ }^{16}$. Il arrive aussi que ce soit l'ange gardien qui présente lui-même le livre de toutes les actions, bonnes ou mauvaises. Telle est ainsi l'opinion du prédicateur Bossuet lorsque, dans son Sermon pour la fête des Saints Anges Gardiens prononcé en 1659, il avertit son auditoire du rôle des anges habilités à porter au ciel les «mérites » comme les « crimes $^{17}$ ». Son rôle se réduit alors à celui d'un témoin et il est dégagé de toute responsabilité dans le Jugement. Il est celui qui guide et qui rend des comptes au moment du trépas, non celui qui décide du sort de l'âme. L'ange gardien est donné au pécheur mais ne peut rien pour lui, la responsabilité de l'homme est seule mise en cause ${ }^{18}$. C'est le thème bien connu du "pèsement de l'âme », saint Michel étant l'archange d'ordinaire préposé à cette tâche ${ }^{19}$. La spécificité de la période qui

15. Association ou Confrérie de la Bonne Mort sous la protection de la sainte Vierge de saint Joseph et des saints Anges Gardiens avec les indulgences et statuts de ladite confrérie, Landriot-Rousset, Riom/Clermont, [s.d.], (la première publication date de 1705), p. 14-15. Outre l'inscription de la fête au sanctoral, c'est le mardi qui a été retenu comme jour spécifiquement dédié aux saints anges, bien que l'on trouve, plus rarement, mention d'autres jours.

16. Philippe Ariès, L'homme devant la mort, Seuil, Paris, 1977 p. 108.

17. Jacques Truchet, La prédication de Bossuet, Cerf, Paris, 1960, vol. 1, p. 195.

18. Sur cette question ainsi que sur la présentation de La Mort du juste et de La Mort du pécheur, voir Louis-Michel Renier, «La catéchèse sur la mort au début du $\mathrm{XX}^{\mathrm{e}}$ siècle. Deux catéchismes en images » in L'image religieuse de la mort, 1890-1990: Une métamorphose, Centre de recherche des Églises de l'Ouest, Université catholique de l'Ouest, n 26-27, 1992, p. 79-100.

19. À ce sujet, $c f$. Giordana Charuty, Folie, mariage et mort, Seuil, Paris, 1997, p. 209-231. 
fait suite à la Contre-Réforme catholique est d'adjoindre au traditionnel archange psychopompe la figure de l'ange gardien assistant personnellement son protégé. Il faut dire que la figure débonnaire de l'ange gardien est évidemment moins redoutable que celle du sévère archange, ce dernier ayant la réputation de n'apparaitre qu'à ceux dont la mort imminente est certaine ${ }^{20}$.

Élément plutôt rassurant : la sollicitude de l'ange gardien n'est pas remise en cause par les péchés de son protégé, malgré la sainte horreur que ceux-ci lui inspirent.

« Ouï, ces Princes célestes nous suivent partout, dans le temps même que nous nous vautrons dans la bouë et dans la fange du péché, qui leur est une puanteur plus insupportable que tout ce qu'il y a de plus infect sur terre. ${ }^{21} »$

Ainsi, à l'heure de la mort, le saint ange gardien manifeste-t-il ses talents consolateurs ; son rôle n'est pas d'atténuer les douleurs physiques, mais bien de consoler l'âme : "C'est dans ce moment si terrible que l'Ange Gardien déploie toute sa charité, toute sa compassion, pour consoler la pauvre âme dans son angoisse ; il dissipe ses craintes, il ranime sa confiance. ${ }^{22}$ »Son action ne se limite pourtant pas à ce soutien durant l'épreuve du trépas. L'ange gardien, en effet, présent tant pendant l'agonie qu'au moment du Jugement particulier, a aussi sa place dans l'économie du Purgatoire. Pendant le temps du Purgatoire, il se tient aux côtés de l'âme dont il a la charge, la réconforte et lui fait part des prières à son intention :

«Non seulement à la mort mais aussi après la mort, le saint ange gardien console l'âme qui lui avait été confiée pendant la vie, quand elle se trouve condamnée aux peines du Purgatoire. On peut croire pieusement qu'il la visite souvent, qu'il la console par sa présence, qu'il l'entretient du compte qu'il a fait de ses dettes, qu'il lui apprend

20. Millénaire monastique du Mont Saint-Michel, t. III : Culte de saint Michel et pèlerinages au Mont, Marcel Baudot (éd.), 1971, Lethielleux, Bibliothèque d'Histoire et d'Archéologie chrétiennes, Paris, 1971, p. 33.

21. Livre de dévotion envers les Sts Anges et en particulier envers le saint ange gardien dont la confrérie est établie dans l'église des RR. P. Minimes du couvent de Nancy, Leseure, Nancy, 1745, p. 25.

22. Semaine angélique de la dévotion au St Ange gardien, Avignon, 1787, p. 84-85. 
le nom des personnes qui offrent pieusement à Dieu le secours de leurs prières pour satisfaire à ces dettes. ${ }^{23}$ »

La figure consolatrice de l'ange rend donc compte à l'âme des suffrages et indulgences en sa faveur, lui délivrant le fameux rafrầchissement $^{24}$. Du reste, l'ange gardien permet aussi au chrétien d'entrevoir les souffrances des âmes du Purgatoire, l'incitant à faire tous les efforts pour s'en prémunir.

« Ils se servent le plus souvent des espèces de notre imagination, et particulièrement pendant la nuit, nous représentant parfois si vivement les personnes que nous avons connues et les peines qu'elles endurent, que nous nous éveillons tout effrayés. C'est une façon qui leur est très commune. $^{25}$ »

Ainsi présentée, la figure du bon ange confirme tant la doctrine du Purgatoire que la dévotion propre aux Âmes du Purgatoire.

«Bien mourir », c'est mourir en chrétien, en membre de l'Église catholique, dûment confessé et repoussant vaillamment les tentations dernières, à l'instar de Charles Borromé dont la fameuse Protestation à l'Ange Gardien, censée avoir été prononcée par le saint à l'article de la mort, est retranscrite dans de nombreux ouvrages de dévotion, à commencer par ceux du père Coret. Tout au long de son testament spirituel, l'archevêque de Milan confie son âme à son ange gardien, qu'il nomme « exécuteur » de sa dernière volonté, laquelle consiste à recevoir les derniers sacrements avant de « mourir en la seule vraie foi que tient et enseigne la sainte Église catholique, apostolique et romaine », et de se déclarer prêt à endurer les peines du Purgatoire...

La «mauvaise mort», au contraire, menace les enfants non baptisés et par conséquent condamnés à errer dans les limbes. Jacques Coret s'en avise et conseille aux parents d'invoquer le bon ange des nouveau-nés afin qu'il les «garde », au moins jusqu'au baptême : «Mais vous, Pères et Mères, écrit-il, appréhendez sérieusement l'obligation de recommander souvent vos enfants

23. Ibid., p. 85 .

24. Cf. Michel Vovelle, Les Âmes du Purgatoire ou le travail du deuil, Gallimard, Paris, 1996.

25. Jacques Coret, L'ange gardien protecteur des mourans, Liège, 1686, p. 281. 
à leurs Anges, surtout, afin qu'ils arrivent aux Saints Fonts de Baptême. ${ }^{26}$ »

La mort est la grande affaire de la vie du chrétien, exhorté à s'y préparer constamment et à multiplier les protections. S'il est une crainte majeure, c'est bien celle de la mort accidentelle et subite qui, par définition, prive l'âme du bénéfice des derniers sacrements. Rien d'étonnant dès lors à ce que les testaments accordent eux aussi à la figure du bon ange une place de choix. «Il est vrai qu'ils peuvent et qu'ils nous procurent quelquefois des biens temporels; mais ce n'est que par accident, et qu'autant que ces biens peuvent et doivent contribuer à notre salut, si nous en faisons un saint usage $^{27}$ » : l'idéalisation de la Bonne Mort figurée par un moribond alité et assisté, prêt à recevoir les ultimes sacrements, va de pair avec ces protections répétées du bon ange qui, encourageant le fidèle, sa vie durant, dans la voie du salut, écarte aussi nombre de périls.

\section{S'EXAMINER SOUVENT}

La meilleure façon de bien mourir consiste à se confesser régulièrement et à «s'examiner souvent». Il est ainsi une habitude, dont l'importance est réaffirmée par l'ensemble des clercs, l'examen de conscience. La littérature de piété répète la nécessité de pratiquer régulièrement, en particulier chaque soir, cet exercice éminemment salutaire et profitable à l'aveu et à la bonne confession. Les Sommes et autres Instructions pour la confession multiplient les conseils, tant aux prêtres qu'aux fidèles. Jacques Coret rédigea par exemple une Manière de bien se confesser et de bien communier (1670), parfois jointe, d'ailleurs, à certaines éditions de L'ange gardien protecteur des mourans. Du reste, les Jésuites sont avant tout des confesseurs, fonction qui est attestée par des juridictions désignant les catégories de la population que chaque père est habilité à entendre en confession ${ }^{28}$. Des confessions en nombre sont rapportées dans

26. Ibid., p. 130.

27. Livre de dévotion envers les Saints Anges, Nancy, 1745, p. 26.

28. Pierre Guérin, Les Jésuites du collège wallon de Liège durant l'Ancien Régime, 1999, t. I, p. 32-33. 
les annales des missions et, au cours de l'une d'entre elles ayant pour centre le collège de Valenciennes, on signale la distribution à 60000 exemplaires d'une « Prière à l'ange gardien, actes de contrition et autres pratiques de piété ${ }^{29} »$.

«Mon saint ange gardien, obtenez-moi la grâce de me bien connoître ; tous les saints et saintes de Dieu, priez pour moi ${ }^{30} »$ : dans les prières conseillées pour l'examen, l'invocation à l'ange gardien est naturellement présente. S'ensuit une impressionnante liste recensant les différentes occasions de pécher. L'examen de conscience peut d'ailleurs s'affiner en examen particulier, travail « ciblé » qui vise à se défaire d'un travers ou à acquérir une vertu. L'un et l'autre participent de ce processus d'individualisation de la piété, exercice sans relâche et mobilisant le soutien de divers intercesseurs, notamment de celui qui sait tout de l'âme dont il a la charge, le bon ange.

Quand, au tout début du XVII ${ }^{\mathrm{e}}$ siècle, François de Sales, dans son Introduction à la vie dévote, recommande des prières au bon ange, qu'il associe à Notre-Dame, à saint Joseph et à d'autres saints, deux moments sont particulièrement appropriés pour cet exercice : le lever et le coucher, temps de l' « examen de conscience». Le règlement de l'Association en l'honneur de la Reine et des neuf chœurs des Anges, et en particulier des Saints Anges Gardiens fondée par Henri-Marie Boudon (1624-1702), grand archidiacre d'Évreux, ancien élève des Jésuites et contemporain de Jacques Coret, insiste sur l'importance de tous les sacrements. Les sacrements de pénitence et eucharistique sont particulièrement valorisés : l'entrée dans la confrérie est sanctionnée par une confession générale et une communion, tandis qu'une communion mensuelle est fortement conseillée. L'Association invite donc ses membres à un examen de conscience régulier, leur offrant un modèle d'exercice de toutes les vertus chrétiennes réaffirmées par le concile de Trente.

29. Cité par Pierre Delattre, Les établissements de Jésuites en France, Institut supérieur de Théologie, Enghien ; Imprimerie Maester Frères, Wetteren, 1949-1957, t. IV, p. 1573.

30. À réciter avant l'examen de conscience. Prières, exercices et pratiques pour les pensionnaires et écolières des religieuses de la congrégation de Notre-Dame, J.-P. Collignon, Metz, 1770, p. 62. 


\section{LA VERTU ANGÉLIQUE}

«Les Anges Gardiens ne procurent pas seulement le salut de quelque chrétien en particulier, ils ne sont pas seulement pour les personnes de certain âge, état, sexe ou condition, Pays ou tempérament, mais pour tous les hommes indistinctement de tous les âges, état, sexe, condition, Pays ${ }^{31} »$, affirme l'un des nombreux ouvrages de dévotion aux saints anges. On peut néanmoins mettre en doute cette affirmation d'indifférenciation, particulièrement en ce qui concerne le sexe ou, comme on le verra bientôt, la « condition ». Il est par exemple établi que l'admission dans l'Association en l'honneur de la Reine et des neuf Chœurs des Anges est gratuite et ouverte aux personnes des deux sexes. On sait aussi qu'une conduite irréprochable est légitimement attendue de la part des membres de la confrérie, notamment l'observance de la chasteté, nommée « vertu angélique »- pour les individus mariés, on parle de chasteté conjugale -, et de la charité. Il serait aisé de croire, à première vue, que ce discours sur l'exercice des vertus chrétiennes s'applique, lui aussi, aux «personnes des deux sexes ». Or, et ce n'est pas une surprise, la conduite des femmes semble davantage préoccuper les clercs que celle de leurs pères, frères et maris.

«Aimez les Anges, ô Vierges, ô Vierges, encore une fois, aimez avec ferveur les Anges, ce sont les grands amis de la Virginité ; ils en sont même les admirateurs, voyant dans des vaisseaux fragiles un trésor si précieux, et des créatures faibles vivre en la terre comme ils vivent au Ciel. ${ }^{32} »$

De même, Jacques Coret, lorsqu'il décrit avec force exemples quels bénéfices on peut attendre de l'ange gardien dans chacun des « cinq états », ne semble s'adresser, pour évoquer les états de célibat et de « viduité », qu'à des jeunes filles et à des veuves, ces dernières étant encouragées à rester chastes, c'est-à-dire fidèles à feu leur mari. Lui aussi présente la dévotion à l'ange gardien comme éminemment profitable à la vertu féminine :

31. Livre de dévotion envers les Sts Anges, 1745, p. 21.

32. Henri-Marie Boudon, La dévotion aux neuf chœurs des Saints Anges et en particulier aux Saints Anges Gardiens, Nancy, 1717, p. 45. 
« Mais que direz-vous si j'ajoute que des Anges ont paru souvent à côté des femmes qui leur étaient dévotes, et les ont ainsi préservées de l'insulte que des vilains leur voulaient faire ! Qu'ils ont arrêté visiblement des marys, ou en les repoussant, ou en leur donnant des soufflets, ou en faisant naître quelque obstacle imprévu, et qu'ils ont empêché, par ces admirables faveurs, le crime épouvantable qu'ils avaient projeté en fait d'incontinence. ${ }^{33}$ »

Puis, dans un chapitre judicieusement intitulé Les Anges défendent les Vierges, il ajoute :

« Chère jeunesse, dans l'âge où vous êtes, que vous êtes chérie de vos aimables Tutélaires! Et que je souhaiterais que vous les amassiez et les honorassiez désormais plus que jamais, puisqu'ils portent leurs dévots spécialement à l'amour et à la conservation de la chasteté. ${ }^{34}$ »

Et, de fait, l'hagiographie légendaire met couramment en scène des anges venant à la rescousse de jeunes vierges dont la vertu est mise en péril. En effet les anges, non contents de les garder, temporairement, de l'acharnement de leurs bourreaux, veillent également sur la chasteté de ces jeunes filles. Cécile a ainsi pour amant un « ange de Dieu » qui préserve sa virginité au-delà même du mariage et favorise les conversions en série, à commencer par celle de son tendre époux et de son beau-frère, tous promis, dès lors, à une inévitable persécution ${ }^{35}$. De même, Agnès, conduite de force au lupanar, y est alors miraculeusement préservée par un ange ${ }^{36}$.

Aux objections avançant la non-incarnation des anges, les Pères du deuxième concile de Nicée (787) répondirent que, bien qu'incorporels, les anges possédaient un corps « subtil », « aérien » et «igné37 » et que leur représentation était dès lors légitime, au même titre que toutes les « saintes images » de Dieu, du Christ, de la Vierge et des saints ${ }^{38}$. Très influencé par les Jésuites, le peintre Francisco Pacheco (1564-1644), qui fut inspecteur des peintures pour l'Inquisition, s'offusque de ce que certains peintres « peignent

33. L'ange gardien protecteur des mourans, p. 136.

34. Ibid., p. 155.

35. Jacques de Voragine, La légende dorée, Seuil, Paris, 1998, p. 639 et sq.

36. Ibid., p. 98.

37. Histoire des conciles œecuméniques, t. IV, Nicée II, G. Dumeige (éd.), Éd. de l'Orante, Paris, 1978, p. 124-125.

38. Ibid., p. 240. 
[les anges] avec le visage et le corps d'une femme et non seulement avec la tête ornée de boucles et de tresses mais aussi avec des seins, ce qui est indigne de leur perfection ${ }^{39} »$ et préconise de les représenter, au contraire, sous forme de « jeunes gens imberbes aux visages beaux et plaisants, aux yeux vifs et brillants ${ }^{40} »$. Au siècle suivant, Honoré Lacombe de Prézel exprimera ce même conseil dans son Dictionnaire iconologique ${ }^{41}$.

Ces recommandations en matière de représentation iconographique méritent toute notre attention au regard du rapport qu'entretient l'ange tutélaire avec la vertu féminine. N'oublions pas cependant que, tandis que certaines catégories de la population sont, dès les $\mathrm{XVII}^{\mathrm{e}}$ et $\mathrm{XVIII}{ }^{\mathrm{e}}$ siècles, spécifiquement concernées par l'assistance des anges dans la lutte contre les tentations, il est un autre protecteur dont font également état les préparations à la mort, les méthodes d'examen de conscience et diverses oraisons privées : le « saint dont on porte le nom ».

\section{BON ANGE ET SAINT PATRON}

« Il n'est pas de Conducteur plus assuré, ni de guide plus clairvoyant, après Dieu et la Vierge, que notre Ange Gardien », peut-on lire dans l'avant-propos d'une édition de L'Ange Conducteur ${ }^{42}$. Il est donc une échelle de valeurs applicable à chaque dévotion particulière. Outre la dévotion au Christ, qui «ne se peut jamais omettre $^{43} »$, la Vierge occupe la place d'honneur, après quoi vient le saint ange gardien. Un autre ouvrage consacré à la dévotion à l'ange gardien avance ainsi des arguments analogues : «On peut dire, sans rien craindre, qu' après la dévotion envers la Sainte Vierge, la Reine des Anges et des hommes, celle envers les Anges et en

39. L'Art de la peinture, Klincksieck, Paris, 1986, p. 243. Ce traité paraît après la mort de Pacheco, en 1649.

40. Ibid., p. 244.

41. Dictionnaire iconologique ou introduction à la connaissance des peintures, sculptures, médailles, estampes, etc., Paris, 1756, p. 20.

42. Édition de 1820, chez Trotot Imprimeur-Libraire.

43. Livre de dévotion envers les Sts Anges..., op. cit., p. 8. 
particulier envers le St Ange Gardien doit tenir le second rang ${ }^{44}$ » et l'auteur de poursuivre " préférablement à tous les saints, chaque fidèle doit avoir une vénération et une dévotion singulières envers son St Ange Gardien. »

Les saints sont ainsi confinés dans une position subalterne et leur rôle minimisé. Si le saint ange gardien, qui vient « juste après la Vierge », fait meilleure figure que ces serviteurs de Dieu, n'estce pas parce que certains échappent encore largement au contrôle de l'Église romaine ? Ce que William A. Christian appelle la « religion locale ${ }^{45} »$ met en effet en jeu l'autonomie d'un saint particulier considéré comme plus efficace dans les limites d'un territoire donné. Davantage sollicitée pour ses pouvoirs propres que pour son rôle d'intercesseur, la figure du saint contrarie aisément l'autorité ecclésiastique, sans compter que le caractère « centrifuge » et coutumier dominant du culte des saints va à l'encontre du centralisme tridentin. À l'inverse, au même titre d'ailleurs que le culte de la Vierge Marie ${ }^{46}$, la dévotion à l'ange gardien est centralisée et cléricalisée ; le culte " civique » à l'ange gardien des localités est rapidement tombé dans l'oubli, tandis que s'imposait son homologue préposé à la garde de l'individu. Le saint patron, le «saint dont on porte le nom », est volontiers présenté comme un modèle (notamment à travers sa Vie ou sa Petite Vie rédigée), le récit exemplaire de sa vie et de sa mort édifiantes devant théoriquement encourager le fidèle à méditer sur les vertus du saint personnage. Or il n'en va pas toujours ainsi, puisque le saint est en effet davantage reconnu en fonction d'un pouvoir, pour ne pas dire une « spécialité ». On pourrait envisager le bon ange personnel comme une solution de rechange en quelque sorte et faire l'hypothèse que ce dernier est mieux qualifié pour exercer cette tutelle disciplinaire : comme on va le voir, il sait tout, entend tout, surveille en permanence son protégé, tout en demeurant affable et bienveillant. L'ange gardien n'est pas un Père

44. Ibid.

45. William A. Christian, Local Religion in Sixteenth-Century Spain, Princeton University Press, Princeton, New Jersey, 1981.

46. Bien entendu, il est aussi des Vierges locales $c f$. Marlène AlbertLlorca, Les Vierges miraculeuses. Légendes et rituels, Gallimard, Paris, 2002. 
Fouettard. Aux yeux de l'autorité ecclésiale, la figure anonyme du bon ange gardien pourrait être regardée comme une solution commode, évitant en tout cas l'écueil des pratiques coutumières ordinairement associées aux saints patrons.

Nombreuses sont les affirmations qui rendent compte de l'intérêt de l'Église à exposer combien ses saints ont été dévots aux anges et combien cette dévotion, qui leur fut si profitable, devrait être adoptée par l'ensemble des fidèles. À cet égard, la fête propre de tel ou tel saint peut être présentée comme un moyen supplémentaire de dévotion aux saints anges : Henri-Marie Boudon recommande d'honorer, à l'occasion de la fête d'un saint, le « Saint Ange qui le gardoit lorsqu'il vivoit ici-bas ${ }^{47}$ ». D’une manière générale, les traités de dévotion aux saints anges se plaisent à rappeler que les saints ont été favorisés par leurs secours, multipliant les preuves dispensées par l'hagiographie $^{48}$. Outre les prières à l'ange gardien et aux archanges, les manuels de piété multiplient les conseils de dévotion à la Vierge (la « Reine des anges »), au saint sacrement, insistent sur l'exercice de la charité et de l'examen de conscience sans oublier, bien sûr, la sainte messe, autant de thèmes privilégiés par la pastorale catholique post-tridentine et avec lesquels la dévotion au bon ange n'entre pas en concurrence, bien au contraire. La dévotion à l'ange gardien, enfin, n'implique ni image miraculeuse, ni relique, ni ex-voto encombrant, ni procession spectaculaire, ni pèlerinage aux confins du terroir, ni même des formules à réciter pour faire venir la pluie ou guérir les animaux. Rien d'étonnant, dès lors, à ce que les grandes écoles de spiritualité - Jésuites, Doctrinaires, Oratoriens, Sulpiciens, Frères des Écoles Chrétiennes, etc. - s'appliquent à en souligner la légitimité. Les anges sont sortis du cadre monastique pour se voir proposés à l'ensemble des fidèles par un nouveau clergé séculier, désireux de promouvoir un culte essentiellement christocentrique et marial. Et les approbations épiscopales vont en se succédant, qui

47. Henri-Marie Boudon, op. cit., p. 370-371.

48. À titre d'exemple, le livre du père Antoine de Saint-Michel, L'Ange gardien (Avignon, 1612), recense un nombre impressionnant de saints favorisés par les bons anges. 
ne trouvent décidément rien à redire sur ces ouvrages de dévotion aux saints anges, rigoureusement conformes au dogme catholique.

\section{FIDÈLE AMI, BON PRÊTRE}

Si le XVII siècle a vu l'avènement de la propagation de cette dévotion à l'ange gardien, diffusion largement tributaire du zèle des membres de la Compagnie de Jésus, mais aussi de toutes les nouvelles congrégations sacerdotales, et sanctionnée par l'inscription de la fête au calendrier romain, le XIX ${ }^{\mathrm{e}}$ siècle va donner une nouvelle impulsion au culte du saint ange gardien, essor qui est d'ailleurs caractéristique de bon nombre de "dévotions nouvelles », qui s'accentuent dans la seconde moitié du siècle, et dont font aussi partie les diverses manifestations de la piété mariale.

«Avoir dans sa chambre ou dans son livre de prière l'image d'un ange, et y jeter quelquefois un regard attentif et affectueux ${ }^{49} »$ : les exercices de dévotion au bon ange s'appuient sur des représentations (images, médailles, statues) qu'il est bon d'avoir à portée de main. Par ailleurs, l'ange gardien est fréquemment assimilé au meilleur ami, c'est-à-dire à un compagnon et confident fidèle et surtout accessible. Cette référence à la stricte intimité est tout à fait logique dans un système qui valorise fortement la dimension domestique de la piété. «Aimez donc ce digne et fidèle ami, priez-le tous les jours, soir et matin, invoquez-le souvent pendant le jour ${ }^{50}$,, exhortent certains catéchismes.

L'ange est volontiers présenté comme un compagnon «zélé », « constant » et « désintéressé », familiarité qui sans doute atténue quelque peu son anonymat. Étant donné les qualités qu'on lui prête, une autre analogie peut alors être établie entre l'ange gardien et la figure du «bon prêtre » : «le bon prêtre doit aussi être considéré

49. R. P. Marie-Félix de Jésus crucifié, Mois de sainte Thérèse suivi de La dévotion aux Saints Anges, Imprimerie du propagateur catholique, Nouvelle Orléans, 1882, p. 131.

50. Jean Couturier, Catéchisme dogmatique et moral - ouvrage utile aux peuples, aux enfants et à ceux qui sont chargés de les instruire,$- 7^{\mathrm{e}}$ édition, t. I, Victor Lagier, Dijon, 1834, p. 198 et 204. 
comme l'ange gardien de nos âmes ${ }^{51} » ;$ l'un et l'autre sont « deux amis sincères que nous devons regarder comme nos anges conducteurs dans les voies du salut ${ }^{52} »$. Modèle idéal, le bon prêtre, entièrement dévoué au salut de ses ouailles, synthétise donc les caractéristiques $\mathrm{du}$ bon ange et illustre encore une fois la valorisation du pouvoir clérical et de la direction de conscience. Cette exaltation du clergé séculier, fortement éprouvé à l'époque révolutionnaire, se voit confirmée par un nouveau modèle de sainteté, celui du saint prêtre. Le cas du curé d'Ars (1786-1859) constitue une illustration éclatante de l'importance de cette nouvelle figure. En 1865, six années seulement après sa mort, la cause en béatification de Jean-Marie-Baptiste Vianney est introduite. Confesseur hors pair, le curé d'Ars jouissait de son vivant d'une solide réputation de sainteté ${ }^{53}$. S'il faut attendre le XIX ${ }^{\mathrm{e}}$ siècle pour que le saint prêtre s'établisse pleinement comme modèle de sainteté ${ }^{4}$, l'évêque de Rodez, François d'Estaing, considéré comme le précurseur du culte officiel à l'ange gardien personnel puisqu'il introduisit la fête du «propre ange » dans son diocèse en $1518^{55}$, affirmait, au tout début du XVI $\mathrm{X}^{\mathrm{e}}$ siècle, que les prêtres étaient des anges guidant le peuple ${ }^{56}$. De même, la spiritualité bérullienne comparait, elle aussi, le ministère sacerdotal et la direction d'âmes à une fonction angélique ${ }^{57}$.

51. L'Ange conducteur des pèlerins d'Ars, ou petit manuel de piété à l'usage des fidèles qui aspirent à la sanctification, Pélagaud, Lyon, 1855, p. 32.

52. Ibid., p. 28.

53. On remarque que ce manuel (op. cit.) paraît du vivant du curé d'Ars.

54. Éric Suire fait remarquer que de nombreuses biographies de prêtres sont rééditées au XIX ${ }^{\mathrm{e}}$ siècle in La sainteté française de la Réforme catholique, Presses Universitaire de Bordeaux, 2001, p. 187-188. Cette préoccupation pour la «sainteté de la vie du prêtre » apparaît aussi dans divers manuels dédiés aux pasteurs : cf. également, Histoire spirituelle de la France, Beauchesne, Paris, 1964, p. 330-337.

55. Camille Belmon, Le Bienheureux François d'Estaing, évêque de Rodez, 1460-1529, Grand Séminaire de Rodez, 1924, p. 369-401. Nicole Lemaître, Le Rouergue flamboyant. Le clergé et les fidèles du diocèse de Rodez, 1417-1563, Cerf, Paris, 1988.

56. Nicole Lemaître (éd.), Histoire des curés, Fayard, Paris, 2002, p. 172.

57. "Mémorial de direction» in Euvres, chap. II, Migne, Paris, 1856, col. 811-812. 
Enfin, tandis que les figures du bon prêtre et du bon ange sont aisément assimilables, l'idée que les anges sont présents dans tous les lieux de culte ayant reçu la consécration doit exciter la piété et le respect des fidèles : "Gardons-nous de les offenser en nos augustes sanctuaires par une attitude irrespectueuse, par une conduite inconvenante, et des distractions volontaires. ${ }^{58} \gg$ Ce postulat du dévouement pose aussi la question de la gratitude du fidèle et les directeurs d'âmes d'insister sur le manque de reconnaissance des hommes devant cette égalité de principe. L'ange gardien devient donc une figure propice à la propagande catholique dans son combat contre l'indifférence religieuse. À cette fin, et ceci n'est pas une nouveauté, la ruralité est présentée comme une souche d'ignorance manifeste : «Il y a un grand nombre de chrétiens, surtout dans les campagnes, qui ne connaissent pas le bonheur qu'ils ont d'avoir des anges pour les garder. ${ }^{59} »$ Mais s'il semble entendu que tout un chacun est veillé par son ange tutélaire, cette affirmation, comme on va le voir, souffre quelques nuances.

\section{UNE ATTRIBUTION SÉLECTIVE}

L'attribution individuelle de l'ange gardien s'accompagne d'une particularisation que rappelle, dans un souci d'exhaustivité, la diversité des modèles de prières énumérant les occasions de l'invoquer : prière du matin et du soir, à l'heure du repas, en voyage, en passant devant une croix, en cas de faute, à l'ange du prochain, etc. Les saints anges investissent le quotidien, il est bon de se recommander à eux en toutes circonstances, et plus seulement à l'heure de la mort. La question de la prise d'effet de la protection angélique personnelle diffère cependant selon les théologiens. On relève trois possibilités : l'attribution de l'ange gardien au moment de la conception, de la naissance, ou encore du baptême. C'est généralement le

58. Bertin Hermans, Les anges dans la tradition catholique, H. Goemaere, Bruxelles, [Imprimatur de 1877], p. 185.

59. De la connaissance des Saints Anges et des devoirs qu'il faut leur rendre, le François, Librairie du Séminaire, Bayeux, 1826, p. 455. 
premier cas de figure qui prévaut, faisant de l'ange un gardien universel.

« Cette résidence commence dès le premier instant de la vie et ne cesse qu'au dernier. Elle embrasse tout le temps de l'épreuve. Elle est continuelle et ne subit d'interruption ni le jour ni la nuit, même dans la vie des plus grands pécheurs. ${ }^{60}$ »

Cependant, la question du baptême et des autres sacrements a son importance, l'ange gardien passant parfois pour être attribué de manière privilégiée aux «fidèles ». Il faut dire que cette question embarrassait déjà les Pères de l'Église dont les avis divergeaient quant à la distribution de la tutelle angélique, certains affirmant que tous les êtres humains en bénéficiaient, d'autres que seuls les chrétiens en étaient dotés et que, même chez les fidèles, l'ange était susceptible de se retirer au vu d'une conduite indigne. Origène émet même successivement les deux conceptions opposées ${ }^{61}$. Thomas d'Aquin, le docteur angélique, ne craint pas les contradictions, puisqu'il affirme tantôt que l'ange gardien est dévolu à l'âme au moment où celle-ci est créée ; tantôt qu'il est attribué seulement au moment de la naissance, l'enfant étant protégé par l'ange gardien de sa mère lorsqu'il est encore dans son sein ${ }^{62}$.

Cette attribution, universelle dans le principe, n'exclut pas une distribution sélective, la valeur de l'ange étant d'autant plus grande que la personne a de «mérite », mérite qui n'est jamais appelé ainsi car attribué à la seule grâce divine. Grossièrement, si tous les chrétiens sont dotés d'un ange, tous ne bénéficient pas, en revanche, d'un ange de même valeur. En effet, si la miséricorde divine est assez vaste pour permettre à chaque pécheur d'être assisté d'un ange gardien et de se sauver, tous les hommes ne sont pourtant pas dignes d'un ange d'égale importance, de la même façon qu'il existe des catégories, qui sont fonction des différents « états » que l'individu est censé pouvoir embrasser. Du reste, l'ange gardien est adapté aux responsabilités

60. Imitation des anges par l'abbé Guillaume Chardon, Librairie catholique, Bellet et fils éditeurs, Clermont-Ferrand, 1891, p. 411.

61. Joseph Turmel, Histoire des dogmes, t. IV, Rieder, Paris, 1935, p. 83.

62. "Ange» in Dictionnaire de Théologie catholique, A. Vacant et E. Mangenot (éds.), Letouzey et Ané, Paris, t. I, 1909, col. 1189-1271. 
de son protégé et certains, comme Monseigneur de Ségur, affirment que les dignitaires sont dotés d'un ange de haut rang : « Les supérieurs légitimes, soit spirituels, soit temporels, reçoivent du bon Dieu qui les élève ainsi en dignité au-dessus des autres hommes, des anges gardiens d'une hiérarchie supérieure, qui les assistent plus efficacement. ${ }^{63}$ »

Ainsi donc, les représentants de l'autorité religieuse et de l'autorité politique sont personnellement assistés par un protecteur céleste plus remarquable que le commun des mortels. Par cette affirmation, Monseigneur de Ségur se situe dans la lignée du fondateur du séminaire de Saint-Sulpice, Jean Olier, qui, au XVII ${ }^{\mathrm{e}}$ siècle, tenait une position analogue :

«Les archanges forment le deuxième ordre de la troisième hiérarchie. Donnés de Dieu aux prélats, ils les conduisent et les dirigent en l'accomplissement de tous leurs devoirs. Les princes de l'Église ont besoin, dans leurs charges, d'une intelligence parfaite et d'une force extraordinaire pour se défendre contre les ennemis de Jésus-Christ. ${ }^{64}{ }$ »

Olier ne fait finalement que reprendre la théorie émise par François Eiximenis au XIV siècle, théorie selon laquelle l'ordre des archanges est gardien du « pape ou lempereur ou aultres grans princes ou prelatz ${ }^{65} »$, ceci pour la raison suivante : les archanges sont dévolus au « bien et exaulcement de la chose publique ${ }^{66}$ ». Il en va de même pour le jésuite Pierre Coton qui considère que les souverains sont spécifiquement dotés d'archanges comme protecteurs ${ }^{67}$. Cet ordonnancement rappelle la structure pyramidale de l'univers dont l'élaboration théorique est couramment attribuée à un prétendu disciple de saint Paul également confondu avec le premier évêque de Paris, le pseudo-Denys l'Aréopagite ${ }^{68}$. L'Aréopagite aurait, à la

63. Mgr de Ségur, Instructions familières et lectures du soir sur toutes les vérités de la religion, 1864, p. 164.

64. Pensées choisies sur le culte de Notre-Seigneur, de la sainte Vierge, des Anges et des Saints, textes inédits publiés par G. Letourneau, Lecoffre/Gabalda, 1922, p. 163.

65. Le livre des saints anges, Guillaume Le Roy, Lyon, 1486, p. 21.

66. Ibid.

67. Henri Bremond, Histoire littéraire du sentiment religieux en France depuis la fin des guerres de religion jusqu'à nos jours, 1916-1933, t. II, p. 117.

68. La hiérarchie céleste, trad. M. de Gandillac, Cerf, Paris, coll. « Sources Chrétiennes », 1958. 
fin du ve siècle, établi une classification appelée à traverser les siècles : le monde angélique est distribué selon neuf « hiérarchies » (encore appelées « chœurs »), elles-mêmes divisées en différents ordres ou « rangs », intermédiaires entre l'homme et la divinité. On trouve, dans la première hiérarchie, les Séraphins, les Chérubins et les Trônes ; dans la deuxième, les Vertus, les Dominations et les Puissances ; les Principautés, Archanges et Anges composant la dernière hiérarchie. Traduite en latin au $\mathrm{IX}^{\mathrm{e}}$ siècle par Jean Scot Erigène, cette Hiérarchie céleste s'introduisit dans l'Occident médiéval. Il faut toutefois se souvenir que l'œuvre du pseudo-Denys ne fait en aucune façon mention de l'ange gardien ${ }^{69}$. Or, par la suite, les neuf chœurs des anges et l'ange gardien seront fréquemment mêlés, à l'image, par exemple, de l'ouvrage du franciscain Eiximenis ou de l'association imaginée par H.-M. Boudon au XVII e siècle.

Indiscutablement, la tutelle pose le problème de l'égalité : tous sont pécheurs, certes, mais tous ne sont pas également pieux, puissants ou saints. Le bon prêtre, déjà, incarne idéalement les vertus de l'ange gardien; le paradigme de la charge - charge d'âmes pour l'essentiel - se dégage, validant l'autorité et les responsabilités des « ministres ». La figure de l'ange gardien prend valeur d'indice dans ce discours que l'ecclésiologie tient sur elle-même et sur la vision de la société qu'elle entend promouvoir.

\section{L'État et la Providence}

Jacques Coret, très préoccupé par le «bien mourir », ne néglige pourtant pas les difficultés de chaque jour. Il préconise en effet des exercices de piété quotidiens à l'égard de l'ange gardien personnel, au sien propre et à celui d'autrui. «Dans toutes vos difficultés, explique celui-ci, ayez recours à lui, recommandez-lui nommément ceux que vous avez en charge, et quand vous avez quelque affaire à démêler avec des personnes difficiles, priez auparavant leurs Anges

69. René Roques, L'Univers dionysien. Structure hiérarchique du monde selon le Pseudo-Denys, Aubier-Montaigne, Paris, 1954, p. 149. 
afin qu'ils les rendent plus traitables. ${ }^{70} » \mathrm{Si}$ la réputation de l'ange gardien lorsqu'il s'agit d' " affaire à démêler» avec des «personnes difficiles » n'est plus à faire, l'idée qu'il est bon d'invoquer les saints anges des « inférieurs » procède de la même volonté d'apaisement social. Il existe des catégories supposées réticentes qu'il faut savoir mettre « en de bonnes dispositions » :

«Les pasteurs invoqueront les bons anges de leurs paroissiens; les pères et mères, ceux de leurs enfants; les maîtres et maîtresses, ceux de leurs élèves ; les chefs de maison, ceux de leurs domestiques ; les supérieurs, ceux de leurs inférieurs. S'ils le font avec confiance, ils ne doivent pas douter qu'ils n'obtiennent, par la protection des anges, des grâces particulières pour les aider à bien gouverner ceux que Dieu a confiés à leurs soins, et pour soumettre les esprits indociles et rebelles, s'il s'y en trouvait. ${ }^{71}$ »

Corollairement, on attend des plus humbles qu'ils invoquent pieusement les anges protecteurs des supérieurs politiques et religieux « surtout lorsqu'ils sont dans la tribulation, ou qu'ils ont besoin de grâces particulières pour soutenir la cause de la justice ou celle de la religion catholique ${ }^{72} »$. Ces «petites gens » sont fermement invitées à accepter leur condition et « bien faire » suivant son «état » est présenté comme un moyen de sanctification.

La particularisation de l'ange gardien affecté à chacun, humble ou puissant, se décline en une variété d'Ange conducteur : on trouve ainsi un Ange conducteur des pèlerins d'Ars ou encore, un Ange conducteur des ouvrières en dentelles de Haute-Loire. Ce dernier ouvrage se veut un manuel édifiant adapté à la condition de ces femmes dont le travail éprouvant est pourtant reconnu et que l'on encourage à accomplir parfaitement leurs tâches ordinaires :

«Vous voyez donc que le véritable moyen de vous sanctifier, ma fille, c'est de bien faire vos actions ordinaires ; car la perfection chrétienne ne consiste pas à faire de grandes choses, mais à bien faire les choses les

70. Jacques Coret, Association pour bien mourir, p. 35-36.

71. Robert Debrosse, Le Mois angélique ou la dévotion à la Reine et aux neuf chours des Anges et en particulier aux saints anges gardiens, André Racle, Bordeaux, 1815, p. 130-131.

72. Ibid., p. 130. 
plus communes, chacun selon sa condition, et l'état où la Providence l'a placé. ${ }^{73}$ »

Il importe avant tout de ne pas se laisser aller à la paresse, en mettant à profit, et sans rechigner, toutes les heures de la journée : «Elle [la bonne ouvrière] doit assigner à chacun des devoirs de son état le moment qui lui convient. ${ }^{74}{ }$ Comme de juste, le lever est traité de manière spécifique, exigeant décence et ponctualité : «Il convient qu'une ouvrière se lève toujours à une heure fixe qu'elle s'habille promptement et avec modestie, comme étant sous les yeux de Dieu et en présence de son Ange conducteur. ${ }^{75}{ }$ Ainsi, l'existence entière de la «bonne ouvrière » est-elle placée sous le patronage de la Sainte Vierge et du bon ange, notamment le lever à heure fixe, l'examen de conscience et le coucher, tandis que les prières multiplient les occasions de les invoquer.

Cette référence aux « états » et à la « Providence » n'est certes pas une nouveauté pour les moralistes : elle s'inscrit dans ce genre de productions littéraires dans lequel les Jésuites s'étaient, semble-t-il, spécialisés, au point d'adapter leur discours à chaque « condition », démarche qui avait en outre pour mérite de s'adresser particulièrement aux femmes ${ }^{76}$. Cette spiritualité des états de vie, qui n'est pas une invention récente, se décline ici en une morale du travail relayée par l'idée de sanctification personnelle. Mais il est un autre public spécifiquement concerné par l'assistance quotidienne des bons anges dans le renforcement de la conscience morale.

\section{LA MISSION ÉDUCATIVE}

«Cette doctrine devrait être enseignée à tous les enfants. Car s'ils éprouvent une respectueuse pudeur en présence de leur père,

73. L'Ange conducteur des ouvrières en dentelle de la Haute-Loire contenant des instructions sur les devoirs des personnes qui suivent cette profession et des prières, Clet, Le Puy, 1840, p. 43.

74. Ibid., p. 19.

75. Ibid., p. 20.

76. Histoire du Christianisme des origines à nos jours, Jean-Marie Mayeur et al. (éds.), Desclée, Paris, t. IX « L'Âge de Raison », p. 864-865. Analyse empruntée à Henri-Jean Martin, Livre, pouvoir et société à Paris, t. I, 1969, p. 144. 
de leur mère ou de leur précepteur, combien plus doivent-ils craindre la présence de leur bon ange et honorer celui-ci », affirmait déjà Jean Gerson ${ }^{77}$ (mort en 1429), à une époque ou s'amorçait à peine une dévotion à l'ange gardien personnel qui concernait surtout les adultes, soucieux de se parfaire dans leur cheminement vers le salut, de s'assurer une bonne mort. En 1853, le concile provincial de Reims encourage les maîtres à enseigner l'importance des anges à leurs élèves, expliquant que « c'est un devoir dont il faut s'acquitter en premier lieu envers les enfants dont l'intelligence, même encore peu développée, saisit facilement cette dévotion et à laquelle s'attache leur âme tendre ${ }^{78} \gg$. Dans de nombreux collèges jésuites, les congrégations des Enfants - congrégations mariales réservées aux plus jeunes élèves - portent le titre de congrégations des Anges (sodalitas angelica $)^{79}$. De fait, l'écolier dévot aux saints anges et à la Sainte Vierge doit tendre vers une forme de perfection chrétienne conforme au modèle exalté par le genre littéraire de L'Écolier vertueux : pieux, humble, obéissant, travailleur, etc. Élève modèle, il est docile, appliqué à l'étude, et sollicite l'avis de son directeur pour ses lectures ${ }^{80}$. Ainsi, parmi les dévotions que les différentes congrégations religieuses proposent à leurs élèves au XIX $X^{\mathrm{e}}$ siècle, la dévotion au bon ange occupe une place de choix, certes bien après la Sainte Vierge.

Tandis que la loi Falloux (1850) favorise l'enseignement confessionnel, nombreux sont les religieux à se consacrer à l'éducation des plus jeunes. Les femmes s'investissent tout particulièrement dans ce domaine avec la multiplication des congrégations dites « actives » (Filles, Sours, Servantes...). Le Manuel de piété à l'usage de la Congrégation des demoiselles de la paroisse de Colmar

77. Cité par Jean Delumeau, op. cit., p. 314.

78. Vincent Klee, Les plus beaux textes sur les saints anges. Écriture, liturgie, magistère, Nouvelles Éditions Latines, Paris, 1984, coll. Angelologia, p. 178-179.

79. Je remercie Louis Schaeffli, de la bibliothèque du Grand Séminaire de Strasbourg, auteur d'un répertoire des confréries alsaciennes (non publié) et qui, pour l'Alsace, signale des congrégations des Anges réservées aux petites classes dans les collèges jésuites de Colmar, Haguenau, Molsheim, Sélestat, congrégations fondées entre la fin du XVI et le début du XVII ${ }^{\mathrm{e}}$ siècle.

80. Manuel de la congrégation des Saints Anges à l'usage de la jeunesse, Desclée-Lefebvre, Tournai, [Imprimatur de 1893], p. 21. 
comprend une prière aux « saints anges gardiens, patrons des écoles du dimanche et du jeudi ${ }^{81}$ » illustrant, une fois de plus, le lien étroit qui relie la figure de l'ange gardien au mouvement de catéchisation. Ces institutions ont notamment vocation à préparer les enfants à la « sainte table », la première communion « solennelle » ayant été dotée d'une liturgie spécifique et généralisée à la fin du XVIII ${ }^{\mathrm{e}}$ siècle. La valorisation grandissante de l'ange gardien par rapport à l'enfance voit le jour à l'époque même où se précise la dimension festive, familiale et sociale de la première communion, au XIX $X^{e}$ siècle. L'ange gardien est alors sollicité lors de cet événement fortement dramatisé, en particulier chez les filles, qui s'apprêtent pour leur noce angélique, tandis que l'hostie est couramment appelée le pain des anges $^{82}$. Mais ce qui est plus frappant, c'est l'analogie établie entre l'enfant arrivé au terme de sa longue préparation et l'ange :

« Je serai un ange, moi, Marguerite, qui y ressemble si peu! Dieu aura effacé mes fautes et mon âme sera blanche comme la neige, pour recevoir le bon Jésus que j' aime tant (...). ${ }^{83}$ »

Ainsi, en Espagne, au début du $\mathrm{Xx}^{\mathrm{e}}$ siècle, certains parents habillaient-ils encore leurs enfants en anges flanqués d'ailes pour l'occasion $^{84}$. On ne peut que constater l'étonnante ressemblance entre ce genre d'implorations et les prières proposées aux mourants. De même, c'est toute la cohorte de protecteurs personnels qui sont mobilisés pour cette « grande affaire » :

« Tous les Anges et Saints du ciel, vous surtout, ô très sainte Mère de Jésus, ma Mère, vous, mon saint Patron et mon Ange gardien, je vous salue avec un profond respect et je vous supplie de daigner préparer mon cœur à Jésus, afin que je sois moins indigne de le recevoir, et d'assister à la sainte Communion que je vais faire. ${ }^{85}$ »

81. 1866, p. $248-249$.

82. L'expression "pain des anges » est aussi utilisée pour désigner l'aumône.

83. Victorine Monniot, Le journal de Marguerite ou les deux années préparatoires à la première communion, t. II, Librairie catholique de Périsse Frères, Paris/Lyon, 1860, (3e éd.), p. 256.

84. William. A. Christian, Visionaries: the Spanish Republic and the Reign of Christ, Univ. of California Press, Berkeley, 1996, p. 247-249.

85. Nouveau recueil de cantiques notés précédés de prières à l'usage du pieux écolier, Rixheim, 1874, p. 55. 
Tandis que les textes normatifs indiquent, par le détail, comment « se disposer » à bien faire sa première communion, l'ange encourage l'enfant, lui désignant le sacrement eucharistique, l'invitant à y prendre part ainsi que le montrent de nombreuses images-souvenirs de premiers communiants ${ }^{86}$.

En parallèle, toute une littérature pédagogique, dédiée en propre aux enfants, voit le jour : les clercs s'illustrent certes dans cet exercice mais, encore une fois, les «dames » ne sont pas en reste dans la rédaction de ces Manuels et autres Instructions. On ne peut pas non plus dissocier la figure du petit ange de ces productions littéraires édifiantes - romans, périodiques illustrés, etc. - dont l'auteur est bien souvent une Mademoiselle, et qui racontent les aventures d'enfants modèles ${ }^{87}$. Selon Claude Langlois, émergent en effet à cette époque « deux nouveaux modèles de sociabilité féminine », la « dame patronnesse » et la « bonne sœur ${ }^{88}$ ». En outre l'ange gardien, classiquement représenté sous les traits d'un jeune homme, tend à se féminiser. Les anges féminins existent dès le $\mathrm{XV}^{\mathrm{e}}$ siècle selon Louis Réau ${ }^{89}$, mais c'est véritablement au XIXe siècle qu'ils vont se multiplier, envahissant une iconographie quasi maternelle. Idéalement, l'ange de l'enfance est celui qui protège, mais aussi celui qui éduque et conduit l'enfant malléable sur le droit chemin. Les éducateurs de la prime enfance, et en particulier ces figures féminines que sont la mère et l'institutrice, laïque ou religieuse, ont ainsi l'ange gardien comme modèle. Par ailleurs, la religieuse enseignante et son homologue laïque doivent toutes deux faire preuve de qualités

86. Dans son ouvrage consacré à l'imagerie de piété en namurois, Jean Pirotte établit des tableaux statistiques faisant état de la fréquence de représentation de divers emblèmes et figures. Sur les images de première communion, on note que les anges sont relativement bien représentés - plus que la Vierge en tout cas -, l'auteur ne commente pourtant pas cette occurrence. Images des vivants et des morts. La vision du monde propagée par l'imagerie de dévotion dans le namurois 1840-1965, éditions Nauwelaerts, Bruxelles, 1987, p. 157.

87. Sur ce type de productions littéraires, on peut consulter l'ouvrage de Marie-Thérèse Latzarus, La littérature enfantine en France dans la seconde moitié du XIXe siècle, PUF, Paris, 1923.

88. «La féminisation du catholicisme » in Histoire de la France religieuse, t. III, Seuil, Paris, 1991, p. 307.

89. Iconographie de l'art chrétien, t. II, vol. 1, PUF, Paris, 1956, p. 34. 
«maternelles». «Qu'est-ce qu'une institutrice?», interroge le Manuel d'une religieuse institutrice ${ }^{90}$. «Une institutrice est une associée des anges. Chaque enfant a un ange député à sa garde pour le diriger dans les voies du salut, le défendre contre les attaques du démon, lui inspirer de saintes pensées ; mais la légèreté de l'âge le rend sourd à la voix de ce guide fidèle, il lui faut un ange visible. » La féminisation du bon ange au profit de ces deux figures essentielles de l'éducation chrétienne s'inscrit dans une époque où la dévotion à la Vierge connaît un vif essor, marqué par la multiplication des congrégations et des apparitions mariales. Cet ange gardien féminisé participe à sa façon de ce vaste mouvement de «féminisation du catholicisme » caractéristique du XIX ${ }^{\mathrm{e}}$ siècle, mis en exergue par Claude Langlois ${ }^{91}$, et dont témoigne le nombre grandissant de congrégations féminines à supérieure générale, congrégations à vocation pour l'essentiel hospitalière ou enseignante.

Cette féminisation de l'ange gardien transparaît aussi dans la mise en scène du danger, représentée sur nombre d'images pieuses et de tableaux. Le ou les enfants cheminent dans une nature, bucolique à première vue, inconscients des périls qui les menacent. Le précipice, la rivière, la forêt servent de décor à cette représentation édifiante d'un ange ailé et très féminisé (longue chevelure, poitrine...) qui protège les « petits » dans un univers périlleux, escarpé ou sauvage. Le motif du "précipice », présent dans toute une littérature de dévotion aux bons anges - les fautes ne sont-elles pas appelées « chutes » dans de nombreux manuels d'examen de conscience ?-, trouve, dans l'iconographie, une expression supplémentaire. L'iconographie post-tridentine de l'ange gardien mettait volontiers en scène un ange masculin accompagnant un enfant sur le modèle de l'archange Raphaël prêtant assistance au jeune Tobie. Idéalement, le protégé était incarné par un enfant, tandis que l'ange gardien n'avait rien de puéril et était représenté sous les traits d'un jeune homme, d'un juvenes. Les fidèles des $\mathrm{XVI}^{\mathrm{e}}-\mathrm{XVII}{ }^{\mathrm{e}}$ siècles étaient invités à imiter cet état d'enfance, à se laisser guider :

90. $1858,3^{\mathrm{e}}$ édition, Lyon-Paris, p. 1.

91. Claude Langlois, Le Catholicisme au féminin. Les congrégations françaises à supérieure générale au XIXe siècle, Cerf, Paris, 1984. 
« Esprits bienheureux, vous qui avez sur moi la même attention qu'un guide fidèle aurait sur un enfant qu'il faudrait conduire à travers les chemins les plus difficiles et les plus dangereux. Je m'abandonnerai donc désormais à vous avec la confiance et la docilité d'un enfant, comme j'en ai la faiblesse et l'ignorance. Que mes chutes, après tout, ne ralentissent point votre zèle. Plus je suis faible et fragile, plus je dois exciter votre compassion. ${ }^{92}{ }^{»}$

À partir de la seconde moitié du XIX ${ }^{\mathrm{e}}$ siècle, le protégé par excellence n'est plus un adulte qui «s'abandonne » à cet état d'enfance, mais bien un enfant. La « congréganisation grandissante ${ }^{93}$ » de l'enseignement en France offre un cadre précis à ce phénomène, dispensant une certaine image du saint ange qui tend à se féminiser, mais aussi, comme on va le voir, à devenir un petit ange.

\section{SURVEILlanCE ET PERSÉVÉRANCE}

Le sommeil est un moment périlleux, essentiellement pour le jeune enfant, d'autant qu'il fonctionne comme une préfiguration du trépas, et nombreuses sont les représentations d'anges gardiens très féminisés, gracieusement penchés au-dessus d'un berceau. Une pratique relevée par Françoise Loux consistait jadis à veiller l'enfant non encore baptisé toute la nuit. La femme préposée à cette tâche allumait des cierges bénits et berçait le nouveau-né en récitant :

« Dors, dors tranquille, joli petit

Tu es bien gardé par le petit ange

Demain nous te donnerons un saint nom

Dors, dors. ${ }^{94} »$

« Tu es bien gardé par le petit ange » : on n'aurait pas parlé en ces termes deux siècles plus tôt ; sans doute, se serait-on contenté d'évoquer la protection du «bon Ange gardien ». Par ailleurs, on

92. Paolo Segneri, La Manne céleste de l'âme, 1738, p. 13.

93. Expression que j'emprunte à Françoise Mayeur, «La formation des institutrices avant la loi Paul Bert. Les Cours normaux » in L'enseignement catholique en France aux XIX et XX $X^{e}$ siècles, G. Cholvy et N.-J. Chaline (éds.), Cerf, Paris, 1995, p. 121.

94. Francoise Loux, Le jeune enfant et son corps dans la médecine traditionnelle, Flammarion, Paris, 1978, p. 136. 
retrouve ici l'idée que l'ange gardien est donné à tous, y compris au nourrisson qu'il protège avant son baptême, c'est-à-dire avant même qu'il ne soit doté de ses propres saints patrons. Si l'association ange/enfant n'est pas récente (qu'on songe seulement au motif iconographique du putto), la tournure que prend cette association au XIX ${ }^{\mathrm{e}}$ siècle constitue en revanche une spécificité. L'enfant peut aussi être assimilé à un "petit ange » dans ce genre particulier de chanson populaire qu'est la berceuse, où il se voit parfois surnommé ange, voire angelet ${ }^{95}$. Les berceuses portugaises mettent fréquemment en scène des êtres maléfiques opposés à des entités bénéfiques et rassurantes, le nouveau-né quant à lui est assimilé à un petit ange anges pouvant aussi se retrouver dans l'ornementation du berceau - mais également à un trésor et au " petit Jésus » ${ }^{96}$. Le petit Jésus qui, soit dit en passant, est également une dévotion spécifiquement proposée aux enfants à partir de la seconde moitié du XIX $X^{\mathrm{e}}$ siècle et qui partage avec l'ange gardien un certain nombre de caractéristiques en dépit d'une dimension sacrificielle puisque, confrontés à son exemple, les enfants sont davantage encouragés à supporter les petites souffrances quotidiennes, « à la manière » du petit Jésus ${ }^{97}$.

Mais surtout, l'ange gardien intègre les Prières $d u$ soir. À l'évidence, le passage au sommeil présente des dangers certains et, depuis la période post-tridentine, l'Église a fréquemment réaffirmé sa «peur obsessionnelle» de la nuit qui, selon Dominique Julia, était avant tout motivée par la crainte des débordements publics et de la licence nocturne ${ }^{98}$. Cette célèbre « peur de la nuit ${ }^{99}{ }$ investit

95. Claudine Antoine, La berceuse populaire dans le contexte de la petite enfance, thèse dactylographiée, Université de Strasbourg II, Strasbourg, vol. 1, 1988, p. 81.

96. Maria-Natalia Ramos, «Le monde enchanté de l'endormissement et de l'apaisement au Portugal » in Les rituels du coucher de l'enfant. Variations culturelles, E. Stork (éd.), ESF, Paris, 1993, p. 235-268.

97. Sandra La Rocca, De l'Enfant Jésus au "petit Jésus ». La dévotion à l'Enfant Jésus dans l'Occident chrétien de la fin du Moyen Âge au milieu du XXe siècle, thèse dactylographiée, Université de Toulouse-le-Mirail/EHESS, 2000.

98. «La réforme post-tridentine en France d'après les procès verbaux de visites pastorales : ordre et résistance » in La Società religiosa nell'età moderna, Guida Editori, Napoli, 1973, p. 396.

99. Rassurer et protéger, p. 338-339. 
dorénavant l'intimité : l'état de faiblesse qui caractérise le sommeil est redouté, car propice aux tentations peccamineuses.

« Tu t'endormiras ensuite paisiblement, en la douce compagnie de ton Ange gardien, de ce même Ange qui, au moment de ta mort, accompagnera ta chère âme et la présentera au Seigneur (...). Tu souhaites le bonjour à ton cher Ange gardien, qui a fait la garde près de toi pendant que tu dormais. ${ }^{100}$ »

Bien entendu, l'invocation de l'ange gardien est aussi présente dans les Prières du matin, où le chrétien est invité à solliciter sa protection pour la journée qui commence. Dans l'un et l'autre cas, l'ange gardien se voit associé à toute une série de protecteurs, au premier rang desquels se trouvent la Vierge Marie, saint Joseph et le saint Patron. Au même titre que le coucher, le réveil est aussi un moment ambigu qui a ses risques propres. Certes, il s'agit pour le bon chrétien d'offrir sa journée à Dieu, mais pas n'importe comment : il importe de se lever promptement et de se vêtir modestement avant de réciter la première prière de la journée. On voit donc émerger la crainte envers deux défauts majeurs, la paresse et l'indécence. De fait, le temps de l'apprêt est lui aussi un temps dangereux qu'il convient d'écourter autant que possible. Ces injonctions à la promptitude et à la modestie contraignent la conduite du jeune enfant, qui ne doit jamais perdre de vue que son inconvenance peut blesser son ange gardien. C'est dès le pieux réveil qu'il faut pratiquer la recommandation. L'ange gardien est alors en bonne place, aux côtés d'autres figures du christianisme :

« Exercice du chrétien

$1^{\circ}$ À votre réveil, faites le signe de la croix et dites: "Mon Dieu, je vous offre mon cœur, mes pensées, mes actions et mes souffrances. Je me recommande à Jésus, Marie, saint Joseph, mon saint Ange Gardien, mon bon Patron."

$2^{\circ}$ Levez-vous promptement, habillez-vous avec modestie, Dieu vous voit, et votre saint Ange. ${ }^{101}$ »

100. Mgr de Ségur, Aux enfants. Conseils pratiques sur la prière, 1873, p. 25-26.

101. Geneviève Bollème, La Bible bleue. Anthologie d'une littérature "populaire», Flammarion, Paris, 1975, p. 262 (Examen de conscience et remèdes contre le péché, XIXe siècle). 
De jour comme de nuit, l'ange tutélaire, en raison de sa capacité de veille permanente, contraint l'enfant à une discipline certaine et son omniprésence doit inspirer, à chaque instant, la crainte de « mal faire » :

«Vous croyez être seuls, ou seulement avec les complices secrets de vos désordres, et votre bon Ange est là qui vous considère, qui vous entend quand vous jurez, quand vous tenez des discours licencieux, quand vous dérobez, quand vous ravagez les héritages, quand vous vous livrez à des actions honteuses. ${ }^{102}$ »

Un spectacle ou des propos inconvenants, certains «vilains défauts », sont aussi présentés comme pouvant affecter directement l'ange gardien : "Quand vous mentez, votre ange gardien se bouche les oreilles et se voile la face. ${ }^{103}$ » À la manière d'une personne respectable, celui-ci mérite certaines marques de déférence et un comportement convenable. Ainsi, il n'est pas un instant où le laisseraller est possible.

« De même, ces chers enfants ne devraient jamais faire quelque chose qui puisse offenser l'ange qui a soin de leur personne, ni jamais faire ce qu'ils ne feraient pas devant le pape, devant leur propre père et leur propre mère, et aussi devant le plus humble de leur compagnon. ${ }^{104}$ »

Le plus grand péril consiste, semble-t-il, à s'écarter de la « voie », à succomber à la tentation. Une fois encore, l'ange gardien peut être un précieux recours.

«Dans la tentation, méprisez l'ennemi, défiez-vous de vous-même, ayez une ferme confiance en Dieu. Dites : "Mon Jésus, miséricorde !" Prononcez le saint nom de Marie, appelez votre ange gardien à votre aide. ${ }^{105}$ »

L'ange gardien « nous inspire de bonnes pensées ${ }^{106}$ » mais, deux précautions valant mieux qu'une, la protection contre de mauvaises pensées passe aussi par une rigueur quotidienne qui exclut toute

102. Jean Couturier, op. cit., 1834, p. 199.

103. Michel Gasnier, Pour la première fois. Retraite préparatoire à la Communion privée, éd. Salvator, Mulhouse, 1958, p. 56.

104. Église Catholique, Les anges, Le Sarment, Paris, 1994, p. 68 (Pie XI s'adressant à des enfants, 1934).

105. Manuel de piété à l'usage de la Congrégation des demoiselles de la paroisse de Colmar, 1866, p. 43.

106. Henri Congnet, op. cit., p. 182. 
probabilité de laisser-aller. Ainsi, face au temps vacant qui constitue une menace sérieuse encourageant l'indolence et l'oisiveté, convientil de s'astreindre à une discipline exigeante, au point d'établir minutieusement des listes répertoriant les bonnes actions, forme d'édification sûre et contraignante. Les calendriers mensuels de «journées pieuses » sont autant d'exemples de cette comptabilité vertueuse. L'obligation morale de «bien remplir sa journée » est aussi, dans la perspective du salut de l'âme et du dénombrement des bonnes et des mauvaises actions, l'obligation de bien remplir sa vie, de mettre à profit le «temps de l'épreuve». Cette compacité renvoie au rôle de l'ange gardien, toujours en alerte, et dont la vigilance est bien supérieure à celle d'éducateurs mortels. Dans le temps si plein et surveillé des élèves de pensionnat, la récréation marque une coupure dangereuse qu'il faut mettre à profit pour se prémunir contre le « relâchement » tant redouté. Aussi exhorte-t-on une fois de plus les enfants à se recommander à leur ange gardien :

« Je vous supplie mon Dieu de me faire la grâce que ma récréation soit innocente; je serais bien malheureuse si je vous contristais en me récréant. Mon Saint Ange je vous conjure, faites-moi connaître si je perds le respect que je dois à mon Dieu, en présence duquel je vais me récréer. ${ }^{107}$ »

L'ange participe à sa manière de ce grand principe éducatif qui consiste à s'assurer que les enfants soient toujours occupés. La multiplication des tâches confiées aux plus jeunes et l'idée d'une surveillance surnaturelle constante relèvent donc de la même préoccupation, celle du temps plein, qui recommande de «tenir » les enfants, en particulier les petites filles ${ }^{108}$. Les garçons, quant à eux, sont plutôt encouragés à être mobiles et à « détester les amitiés particulières » : «Ne jamais y rester oisif [pendant le temps de la

107. Instruction chrétienne des jeunes filles dressée en faveur de celles qui y sont instruites dans la communauté des Dames de la Croix; pour y servir de lecture. Tirée pour la plus grande partie du livre de l'Instruction de la jeunesse fait par M. Gobinet..., Le Clerc, Berton, Paris, 1734, p. 29, extrait cité par Martine Sonnet, L'éducation des filles au temps des Lumières, Cerf, Paris, 1987, p. 163.

108. Yvonne Verdier a précisément décrit ce souci d'occupation constante des filles in Façons de dire, façons de faire, Gallimard, Paris, 1979. 
récréation]. Ne pas former de groupe, ni entamer de longues conversations, mais jouer, et, autant que possible, à des jeux qui exigent beaucoup de mouvement », recommande à cet égard le Manuel de la congrégation des Saints Anges à l'usage de la jeunesse ${ }^{109}$. Cet ange, qui « considère » en permanence son protégé, voit tout, entend tout, empêchant finalement l'enfant d'être « livré à lui-même », car constamment soumis à la mauvaise conscience, voire à la honte, que cette présence édifiante est censée lui inspirer. Il rappelle en permanence le chrétien à ses devoirs, auxiliaire de la constance, définie comme une lutte ferme contre les obstacles extérieurs et les passions.

Quand, au XVII ${ }^{\mathrm{e}}$ siècle, les fidèles étaient invités à préparer leur salut avec le soutien de divers intercesseurs et au moyen d'une comptabilité étourdissante de grâces et d'indulgences, la population féminine, présentée comme plus vulnérable à la tentation, pouvait compter sur la sollicitude toute particulière du bon ange personnel. Puis, de la bonne ouvrière à l'enfant modèle, sont allés se répétant ces mêmes conseils indiquant de «se lever promptement», de «s' habiller avec modestie » et de «s'entretenir de bonnes pensées », autant de recommandations réitérées par un genre littéraire spécifique : $L a$ Journée du chrétien. Cette pieuse littérature d'édification dit toujours les mêmes dangers et redoute toujours les mêmes fautes, tandis que le bon ange veille...

68 Bd de la Libération 13004 Marseille annemanevy@voila.fr

109. Op. cit., p. 37. 



\section{EASR \\ www.easr.de www.iahr.dk www.rahr.ro}

The European Association for the Study of Religions The International Association for the History of Religions The Romanian Association for the History of Religions

6TH EASR CONFERENCE

IAHR SPECIAL CONFERENCE

\section{RELIGIOUS HISTORY OF EUROPE AND ASIA}

\section{BUCHAREST, 20-23 SEPTEMBER 2006}

CO-ORGANISERS:

Agence Universitaire de la Francophonie

Romanian Cultural Institute

The Centre for the History of Religions, University of Bucharest
Christianity in Late Antiquity

- Greek and Roman Religions

- Hermetic Traditions and Esotericism

Indian Religions

- Iranian Religions

- Mircea Eliade and His Legacy

- Monotheisms in the Middle Ages

- Religious Interactions between Eastern and Western Europe

- The Reception of the East as the 0ther 


\section{ÉDITIONS DE L'HERNE - CAHIERS D'ANTHROPOLOGIE SOCIALE}

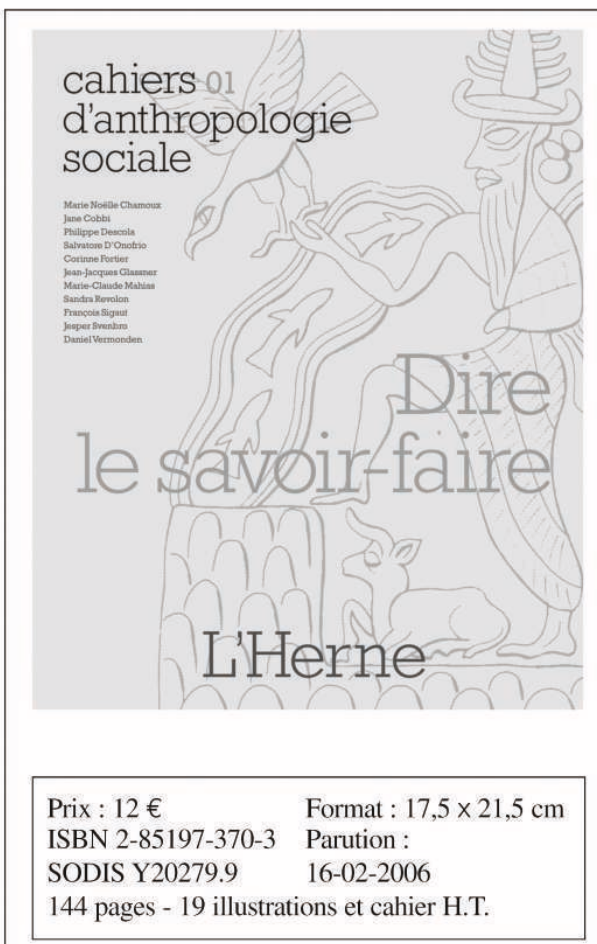

\section{Contributeurs}

\section{Philippe Descola}

Introduction

Jean-Jacques Glassner

Savoir et savoir-faire en Mésopotamie

Jesper Svenbro

Les démons de l'atelier.

Savoir-faire et pensée religieuse dans un poème d' « Homère »

\section{Marie Noëlle Chamoux}

Dire le savoir-faire en nahuatl classique

\section{Corinne Fortier}

Intelligence pratique du berger et art magique du forgeron dans la société maure de Mauritanie

\section{Salvatore D'Onofrio}

«Toute chose a son galbe».

Style et savoir-faire en Sicile

\section{Daniel Vermonden}

Kapande et kaparika.

Deux manières d'être habile et cultivé à Buton (Sulawesi, Indonésie)

\section{Sandra Revolon}

Manira (Aorigi, est des îles Salomon)

\section{Jane Cobbi}

Le «pays de la main ».

Waza ou le savoir-faire au Japon

\section{Marie-Claude Mahias}

Savoir ou faire en Inde

François Sigaut

Le savoir des couteaux

\section{Nouvelle collection}

Cahiers d'anthropologie sociale $N^{\circ} 01$ Dire le savoir-faire - (dirigé par S. D’Onofrio - F. Joulian)

Nous vivons dans une époque de mutation anthropologique provoquée, dans une large mesure, par la séparation entre les hommes et leurs outils. Cette véritable « catastrophe anthropologique ", dont nous sommes tous en même temps responsables et victimes, s'accompagne de la désintégration qu'ont produite dans les sciences sociales les notions réductrices d'Homo æeconomicus, d'Homo religiosus, ludens, ou videns. Cette désintégration est illustrée aussi bien par la création de clones que de nouveaux individus capables de tout consommer, depuis les produits transgéniques jusqu'à la viande d'animaux que nous avons transformés en « cannibales ».

Étudier le savoir-faire dans les sociétés traditionnelles peut donc devenir une vraie ressource, puisqu'on fait alors appel à des modèles qui peuvent montrer à plusieurs niveaux la relativité des idéologies dominantes.

Ce programme apparaît d'autant plus intéressant que nous vivons dans une civilisation capable de constituer des archives très sophistiquées de la mémoire sociale, alors même qu'elle est en train de vider l'humanité des appareils symboliques et conceptuels élaborés tout au long de son histoire.

Dans diverses sociétés, les savoir-faire s'expriment par des concepts et des mots dont la valeur sémantique dépasse souvent le cadre des gestes techniques, tâches ou contextes d'utilisation. Et quoique dans certaines cultures le savoir-faire puisse être très développé sans avoir pour autant d'expression linguistique, il existe néanmoins, couramment, une relation étroite entre l'investissement corporel et les catégories stylistiques auxquelles appartiennent les objets. Les articles qui composent ce numéro explorent ces questions dans des sociétés fort éloignées dans le temps et dans l'espace et relancent le débat autour des pratiques techniques et de leurs modes de transmission.

Éditions de L'Herne

\section{2, rue Mazarine, 75006 Paris}

Tél. : 0146330300 - Fax : 0146330301

lherne@wanadoo.fr - www.editionsdelherne.com

Service de presse sur demande

\section{Rédaction :}

Laboratoire d'anthropologie sociale

Collège de France

52, rue du Cardinal-Lemoine

75005 Paris

Tél : 0144271745 - Fax : 0144271766 cahiers.las@college-de-france.fr 


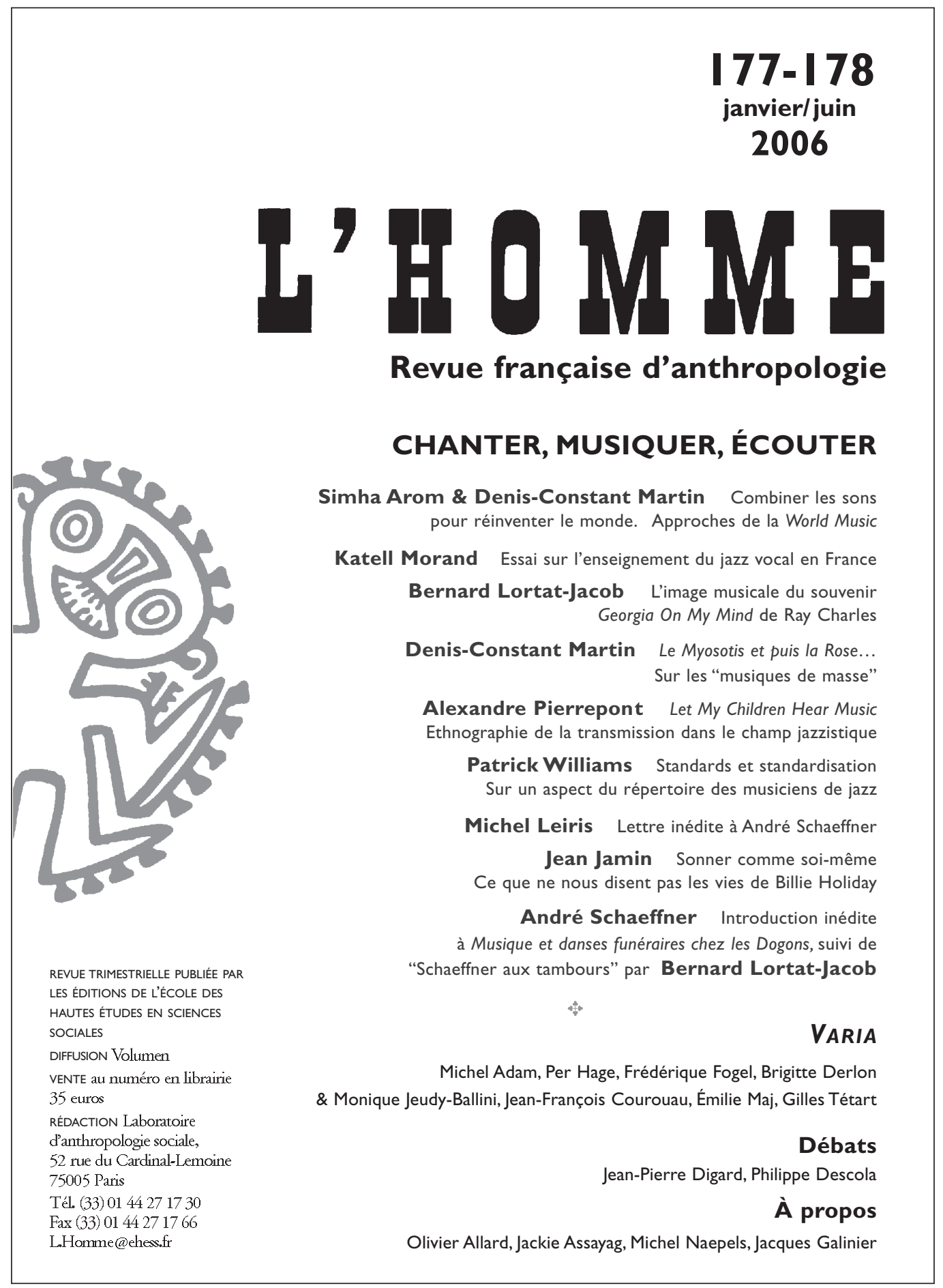

